\title{
Supply Chain Management 4.0: A Literature Review and Research Framework
}

\author{
Chaimaa Bentaher and Mohammed Rajaa
}

\section{ABSTRACT}

Supply chain management is constantly evolving. The business world is transitioning from one paradigm to the next. In the corporate sector, supply chain 4.0 is the most recent trend. This article examines and analyses the existing state-of-the-art literature on Supply Chain Management 4.0 (SCM 4.0) and the interaction between digital technologies and Supply Chain Management. A bibliometric study and a literature assessment of state-ofthe-art publications in the relevant topic were done. The impact of emerging technology on various supply chain operations is examined in this research. In addition, the study establishes a foundation for future research and practice. Because it describes the pillar components for any supply chain change, the suggested work is valuable for both academics and practitioners. It also suggests a set of study questions that might be utilized as a foundation for the field's future research. This research presents a fresh and original literature review-based study on SCM4.0, as there is currently no comprehensive evaluation accessible that includes bibliometric analysis, motives, impediments, and the impact of technologies on distinct SC processes.

Keywords: Advanced technologies, Industry 4.0, Innovation, MCDM, SCM4.0.

\section{INTRODUCTION}

The way societies communicate information and interact has been profoundly altered by digital technology (Emelogu et al., 2019). The way individuals communicate, and share information has changed as a result of technological advancements. The logistics, supply chain, manufacturing, and transportation industries will all be impacted by this new technology. As a result, every industry's future will be dependent on innovation and technology. With the fourth industrial revolution, every industry is undergoing a rapid shift.

All business settings and industries are undergoing fast changes. Because today's marketplace is characterized by fierce rivalry, cost pressures, short-term market demand, and dynamic demand patterns, supply chains can no longer be repositioned overnight to buy, create, move, or sell the correct things in the right quantities and places $(\mathrm{H}$. Wu et al., 2017). As a result, a supply chain must be imagined in which commodities, processes, and structures may be easily changed in response to changing situations. As a result, supply chains must become intelligent in order to successfully deal with the increasing difficulties (Wu et al., 2014). Several distinct words have been used in the literature to characterize supply chain 4.0, including smart supply chain, digital supply chain, and intelligent supply chain. We use the words supply chain 4.0 and digital supply chain interchangeably in this text. The fourth industrial revolution has ushered in a new digital era, which has given rise to supply chain 4.0 (Ardito et al., 2019). Many technologies, concepts, and methodologies are included into Industry 4.0 to enable production systems' autonomy, flexibility, dynamism, and precision (da Silva et al., 2019).

The goal of this research is to discover and assess the link between digital technologies and supply chain management (SCM). As a result, the following factors make this research significant: (1) Supply Chain Management 4.0 (SCM 4.0) is a complex field (Emelogu et al., 2019); (2) SCM 4.0 research is a current issue (Abdelkafi \& Pero, 2018; Addo-Tenkorang \& Helo, 2016); and (3) recent technological advances have had a direct impact on the performance of supply chains (SCs) (Al-Doori, 2019). Furthermore, businesses must recognize the importance of integrating cutting-edge technology with physical operations in order to provide visibility and connectivity in their SCs (Ameri \& Patil, 2012). As a result, it is critical to have a broad discussion on the subject.

The adoption of SCM 4.0 has gotten a lot of press. More than 300 papers have resulted from the contributions of many academics and practitioners to this field's research. Only a few studies have attempted to evaluate smart SCs or digital SCs (Kang et al., 2016; Gebresenbet et al., 2018; Bu et al., 2020). Through a systematic literature analysis, AddoTenkorang \& Helo (2016) investigated the implications of big data for sustainable supply chain management. AddoTenkorang \& Helo (2016), like other studies, concentrated on a single technology: big data. Wu et al. (2016) also did a 
literature analysis in order to conceptualize the characteristics of smart supply chains, as well as define and investigate five important research areas, including information management, IT, process automation, advanced analytics, and supply chain integration. In a similar vein, Abdelkafi \& Pero (2018) conducted a literature review to contextualize IT in a supply chain 4.0 scenario, with a focus on the supply, production, and final consumer phases. Finally, Barholomae (2018) identified key limitations and prospects in DSCs, summarizing prior research and identifying knowledge gaps by providing advantages, weaknesses, and limitations of individual methods and developing a framework for future research and practice by providing advantages, weaknesses, and limitations of individual methods and developing a framework for future research and practice. In other words, this study provided a review of the literature on DSCs and their enablers as well as a framework. However, the impact of enablers on different $\mathrm{SC}$ processes was not defined in the study. According to the information examined, there is a lack of a clear framework for understanding and building SCM 4.0.

Traditional SCs and I4.0 (Industry 4.0) have received different attention in studies and research. As a result, studies on SC4.0 are still relatively new, and only a small number of them are available in bibliographic databases (Backhaus \& Nadarajah, 2019). In this context, there is no thorough assessment available that considers bibliometric analysis, incentives, impediments, and the impact of technologies on various SC activities. Furthermore, there are no academic studies that expressly propose a paradigm for integrating SCM4.0 with risk management in the digital world. A literature review was done to address these gaps in the academic literature. As a result, the paper aims to fill a vacuum in previous research surrounding the development of a comprehensive conceptual framework for SCM 4.0 implementation. Its goal is to provide readers with a distinct perspective on SCM4.0 and to demonstrate the impact of various technologies on SC procedures.

This article is organized as follows: in the next section (Section II), we outline the study's review process. The descriptive results are presented in Section III. The bibliometric analysis is shown in Section IV. Section V highlights significant enabling technologies, research contributions, motives, and barriers in the development of SCM4.0. The proposed framework is presented in Section VI. Finally, the last section examines research gaps, practitioner implications, and future research directions.

\section{RESEARCH METHODOLOGY}

A literature review assists authors in evaluating and analysing relevant literature, as well as identifying the field's conceptual content and contributing to theory development (Carvalho et al., 2019). Because the SC4.0 subject is still very new, there are a lot of related publications out there. We categorized academic and industrial journals by analysing their titles, abstracts, and articles in traditional and electronic library systems due to a lack of clear keywords that describe SCM 4.0.

The review methodology was based on the content analysis approach shown in Fig. 1 (Kamble et al., 2018b) to address the study objectives:
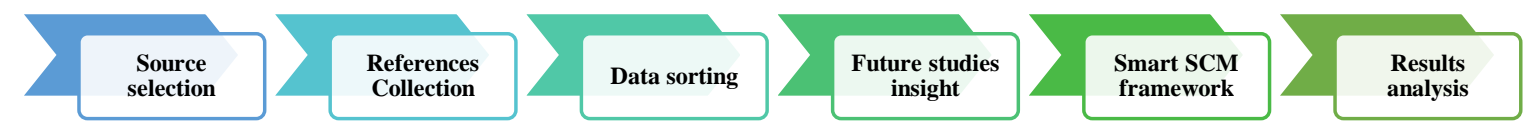

Fig. 1. Methodology`s review (Author`s illustration)

The following databases were utilized to search for relevant papers in order to find the broadest possible range of scholar productions:

(1) Scopus (www.scopus.com),

(2) Elsevier (www.sciencedirect.com),

(3) Emerald (www.emeraldinsight.com),

(4) Springer (www.springer.com),

(6) Google Scholar.

The keywords and terminology utilized in the database searches were those that are often used to characterize and define the usage of digital technology in supply chain management. The authors' keyword choices are listed in Table I. The literature review was carried out utilizing a variety of research dissemination sources, including highimpact scientific journal papers and indexed conference proceedings. The inquiry technique was devised after a thorough examination of the available data sources. The literature review included the years 1994 through 2021, as the concepts of machine learning, EDI, and AI (Artificial Intelligence) had been around since 1994. Table I shows a summary of the method used.
TABLE I : RESEARCH OVERVIEW (AUTHOR`S ILLUSTRATION)

\begin{tabular}{|c|c|}
\hline Type of analysis & Qualitative \\
\hline Period of analysis & $1994-2021$ \\
\hline $\begin{array}{l}\text { Keywords used in the } \\
\text { research }\end{array}$ & $\begin{array}{l}\text { Digital transformation, } \\
\text { Digitalisation, } \\
\text { Smart Supply chain management, } \\
\text { Digital Supply chain management, } \\
\text { Virtual value chain, } \\
\text { Intelligent value chain, } \\
\text { Smart Value creation, } \\
\text { Cyber-physical systems (CPS), } \\
\text { Big data (BD), } \\
\text { Cloud manufacturing, } \\
\text { Internet of things (IoT), } \\
\text { Blockchain, } \\
\text { Augmented reality (AR), } \\
\text { Additive manufacturing, } \\
\text { Industry } 4.0\end{array}$ \\
\hline $\begin{array}{l}\text { Total number of articles } \\
\text { evaluated }\end{array}$ & 387 articles \\
\hline Software tools & $\begin{array}{l}\text { Microsoft Power BI } \\
\text { Zotero } \\
\text { Bibliometrix } \\
\text { MAXQDA }\end{array}$ \\
\hline
\end{tabular}




\section{RESULTS}

The descriptive statistics based on the analysis of the 387 papers discovered through the literature review are presented in this section. The section illustrates the literature trend in terms of paper publication over time, geographical application area, journal distribution of reviewed articles, and field-enabling technologies.

To observe the progression of research interest, we started by graphing the number of publications over time. The goal of evaluating the literature throughout time was to look at the advancement of SCM 4.0 research year by year. In the recent past, it was seen that SCM 4.0 had become a subject of research interest among academics and practitioners (see Fig. 2). Between 1994 and 2021, the 387 papers found were published. From 1994 to 2015, the number of published papers on SCM 4.0 research was minimal, with an average of 1, 2 or 4 articles published every year. There was a huge growth from 2015 to around 60 papers in 2019.85 .23 percent of the publications were published between 2016 and 2021, according to the findings. As a result, the number of studies on this subject has increased in recent years. As a result of the growing awareness among scholars and practitioners, SCM 4.0 is emerging as a research field. Furthermore, with an increasing number of enterprises focusing on the digitalization of their SCs, research in this area is likely to continue to expand.

The 387 publications on SCM 4.0 research that were chosen were published in 88 journals. The broad scope of journal coverage indicates the growing importance of SCM 4.0 research. Fig. 3 depicts the periodicals that have published publications about SCM 4.0. Only journals that publish at least three publications are included in the graph. We looked at the rankings provided by the SCImago Journal Rank (SJR) platform to determine the publications' scientific impact.

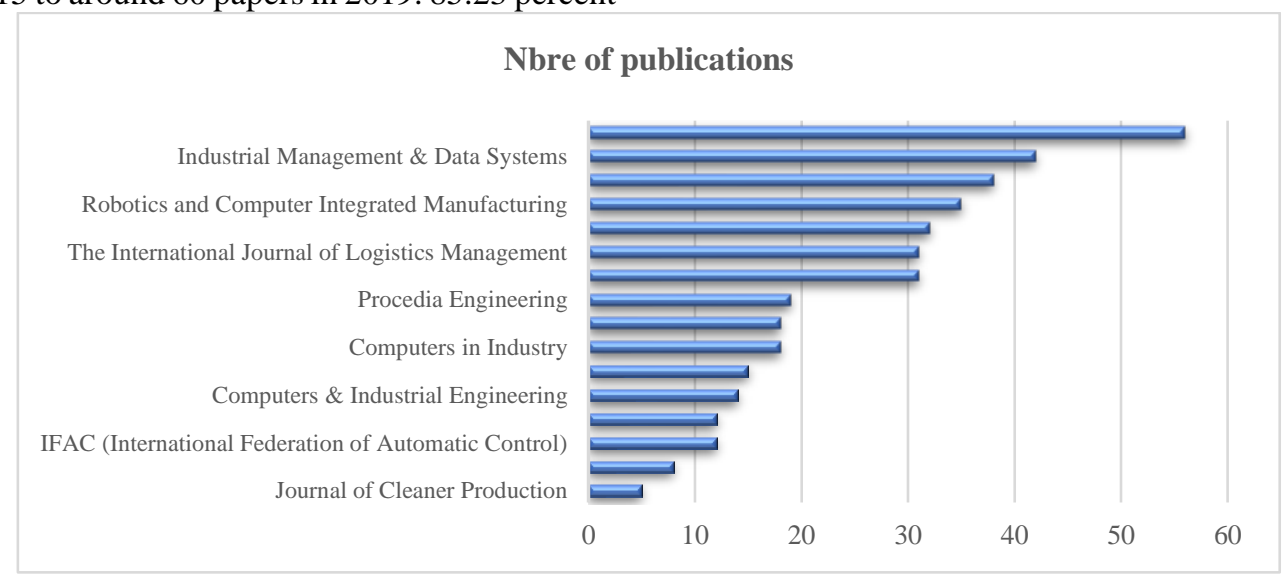

Fig. 2. Number of publications reviewed by journal regarding intelligent supply chain (Web science).

Manufacturing (Q2), FAC (Q2), and Procedia Engineering, all the journals shown in Fig. 2 are in the Quartile 1 (Q1) group.ssss

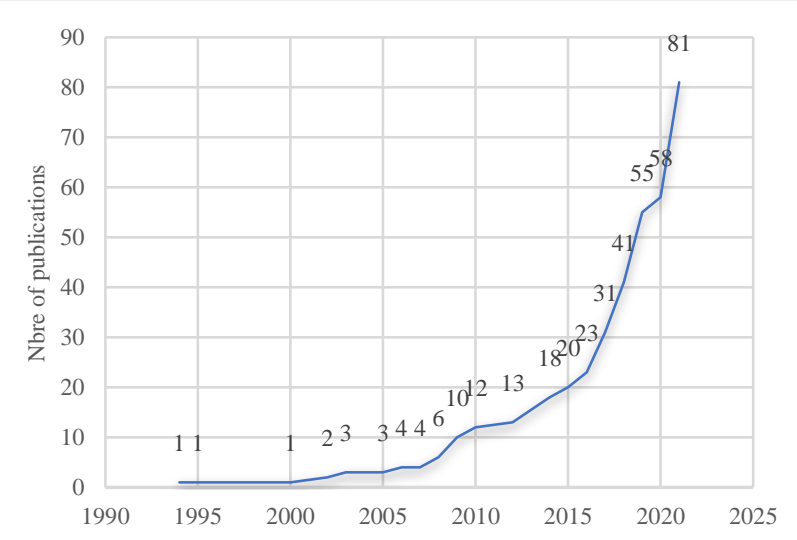

Fig. 3. The amount of publications / year through the period of analysis (Author`s illustration).

It may be stated that SCM 4.0 research will most likely be published in a variety of specialized publications (SCM, production, computers industry). In addition, the theme is acceptable for publication in technological publications. This could explain why SCM 4.0 research papers have been published in a variety of journals.

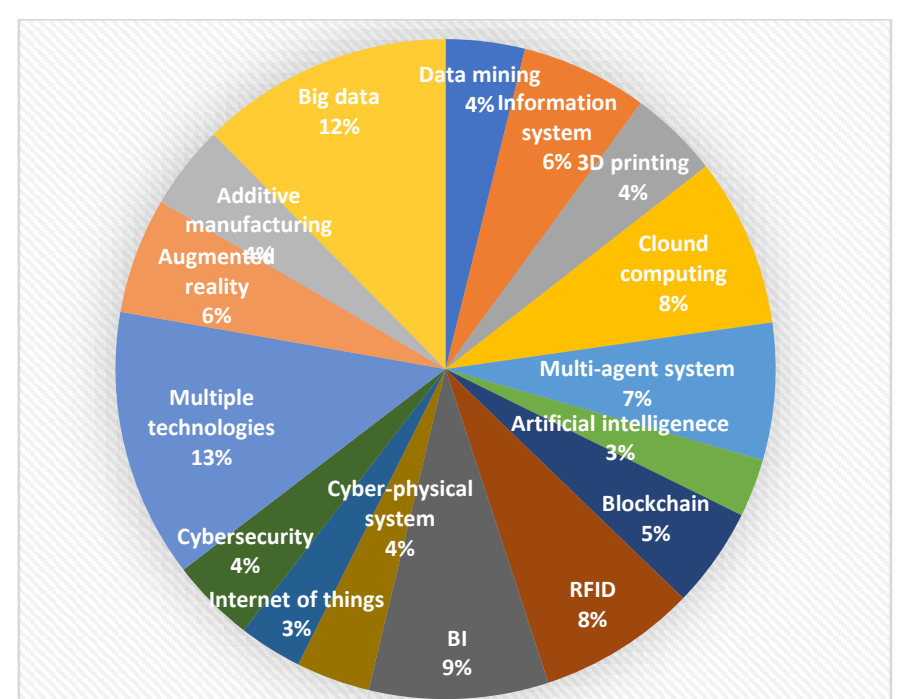

Fig. 4. Number of papers published in relation to technologies (Author`s illustration).

\section{BIBLIOMETRIC ANALYSIS}

"Supply chain" was the most often used word, appearing 157 times, followed by "management," "I4.0," "technology," "data," and "digital," which appeared 29 times. The usage of each phrase in the studies via the literature was mapped using those frequent words. This can be used to characterize the work, place it in context, or give a quick rundown of its contents. It aids in capturing the reader's attention. We can 
see that the examined papers' titles discuss SCM in conjunction with I4.0, technology, or data. In other words, the title's summary suggests that the mixed topic of SCM and innovative technologies has the potential to engage the academic community on a long-term basis.

TABLE II : KEYWORDS CATEGORIES (AUTHOR`S ILLUSTRATION)

\begin{tabular}{lll}
\multicolumn{1}{c}{ Green Category } & \multicolumn{1}{c}{ Blue category } & \multicolumn{2}{c}{ Red Category } \\
3D printing & IoT & AI \\
Additive & Augmented reality & Operation management \\
manufacturing & Machine learning & Blockchain \\
Supply chain & Risk management & Industry 4.0 \\
Value chain & Supply chain integration & Smart manufacturing \\
& Logistics & Supply chain resilience \\
& SCM & Supply chain risk \\
& Sustainability & management
\end{tabular}

The abstract co-occurrence metric measured the relatedness of abstract words based on the number of texts in which they appeared at the same time. Fig. 4 shows the cooccurrence network built from the abstracts of the papers studied. A term's minimum number of occurrences was 30 . Only 51 of the 4,210 words passed the test, and 33 were filtered. The red, blue, and green category are depicted in Table II. "SCM," "big data," "Internet," "Internet of Things," "data," "information," "application," and "product" are all part of the green category. "Blockchain" and "technology" are included in the blue category. Thus, the presence of digitalization words was discovered in the abstract. It can be deduced that the "data" or "information" portions of supply chains are being prioritized. To put it another way, data assists firms in developing new growth prospects, which may explain why researchers are interested in exploring the application of big data in SCM.

\section{DISCUSSION}

This section discusses the selected SCM 4.0 works as well as the results of previous analyses. Based on the results of such analyses, the most relevant technologies for SCM 4.0 are examined. Their implications for SC processes are also discussed

Globalization has thus far resulted in higher income, owing to the rapid expansion of earnings. Businesses will be able to deal with performance difficulties as supply chains become smarter. Porter \& Heppelmann (2014) advocated for the importance of having smart SCs in this scenario. Using Interpretive Structural Modeling, Ghobakhloo (2018) developed, constructed, and studied eleven parameters that influence the deployment of smart manufacturing information and digital technologies. Ghobakhloo (2018) drew out the contextual interrelationships between elements, leading to a better understanding of smart manufacturing transformation processes and environments that support industrial digitalization in the industry 4.0 era. Furthermore, Maresova et al. (2018) investigated the effects of digitalization and Industry 4.0 on the ripple effect and supply chain disruption risk control analytics. They offer a study paradigm that combines the effects of digitalization on SC management (SCM) and SCM on ripple effect control. Gebresenbet et al. (2018) also investigated how multinational companies in five industries have adapted to SC 4.0. Big data, cloud computing, and 3D printing were the three key developing technologies they focused on. They have created a graphical framework to describe the concerns that have been debated about Supply Chain 4.0.

Our research revealed that four publications (Ameri \& Patil, 2012; Addo-Tenkorang \& Helo, 2016; Ardito et al., 2019; Emelogu et al., 2019) present a literature review on SCM 4.0. Ameri \& Patil (2012) provide an overview of the literature on DSCs and their enablers, as well as a framework for their integration. Various writers have proposed different frameworks for SCM 4.0 (e.g. Bhatti et al., 2016; Chukalov, 2017; Ardito et al., 2019). For example, Bhatti et al. (2016) used the SCOR model to construct a conceptual framework that led to the development of a survey instrument to investigate the usage of emerging digital technologies in supply chain core management. A framework for IT-enabled supply chain integration was proposed by Chukalov (2017). Ardito et al. (2019) developed a model that provides a novel and complete assessment of the new concepts and components that are driving fledgling and emerging industries.

SCM 4.0 has been used by certain authors to address the sustainability issue. Kamble et al. (2018), for example, investigated the impact of digital transformation technologies on long-term supply networks. However, this research was limited to the social and environmental aspects. Quarshie et al. (2016), on the other hand, looked into the impact of sustainability on supply chain 4.0 performance. These two studies, however, are insufficient to provide a comprehensive picture of the joint influence of sustainability and SC 4.0. Furthermore, risk management in the context of SCM 4.0 has received less attention. Several authors, like Khan et al. (2021), have addressed the digitalization of SC risk management. In other words, they've concentrated on how to manage risk effectively. The focus on SCM 4.0 has been mostly on its enablers, as evidenced by the research reviewed. Table I categorizes the contributing publications to SCM 4.0 and its technologies that focus on SCs.

SCs 4.0 can be managed using a variety of technologies or methodologies. CPS, IoT, CC (cloud computing), blockchain, $\mathrm{BD}, \mathrm{AR}$, and $\mathrm{AI}$ are only a few of these technologies (Attaran, 2007; Ben-Daya et al., 2017; Buy€ uk€ €ozkan and G€oçer, 2018; ElMaraghy, 2019; Min, 2019; Nguyen et al., 2018). Appendix 2's Table A1 lists the many definitions of these technologies:

All the aforementioned technologies have an impact on the SC. BD has a favorable impact on both supply chain and organizational performance (Bhatti et al., 2016). By promoting operational brilliance, cost reserve funds, and consumer loyalty, it can impact the production network. SC supervisors can use $\mathrm{BD}$ to strengthen their firms' relationships with customers and suppliers, as well as increase replenishment through better stock management (Stock \& Seliger, 2016). In terms of assisting managers in understanding supplier performance, BD is beneficial (Bhatti et al., 2016). Better projections, increased SC visibility, and strong SC relationships are all benefits of BD (Babiceanu \& Seker, 2016). The application of BD in production planning and control is still in its early stages (Tien et al., 2019). The SC benefits from BD, particularly in demand forecasting, procurement, inventory, and reverse logistics (S. Agrawal et al., 2015). 
European Journal of Business and Management Research www.ejbmr.org

TABLE III : AUTHORS CONTRIBUTIONS IN INTELLIGENT SUPPLy CHAIN MANAGEMENT (AUTHOR`S ILLUSTRATION)

\begin{tabular}{|c|c|c|}
\hline Authors & Year & Contribution \\
\hline Al-Mudimigh et al. & 2004 & $\begin{array}{l}\text { Because of its simplicity and openness, this work illustrates that using XML for communication } \\
\text { implementation in the SC has advantages. The implementation of such a method, which permits } \\
\text { the communication of heterogeneous systems by modifying a neutral data format, is discussed in } \\
\text { this study. }\end{array}$ \\
\hline Christopher & 2005 & $\begin{array}{l}\text { The authors created a framework for using knowledge discovery techniques in automated SC } \\
\text { configuration. }\end{array}$ \\
\hline Carbone \& Gouvernal & 2007 & $\begin{array}{l}\text { The study discusses the problems of RFID installation, as well as the stages of adoption and } \\
\text { success criteria. It also goes into the difficulties of integrating RFID with existing supply chain } \\
\text { management, customer relationship management, and ERP systems. }\end{array}$ \\
\hline Zare Mehrjerdi & 2009 & $\begin{array}{l}\text { This article examines the function of data structures in SCM software and proposes a data } \\
\text { structure for usage in SCM systems' scheduling routine. }\end{array}$ \\
\hline Vatovec & 2011 & $\begin{array}{l}\text { To examine safety hazards in food SCs, this research proposes a new food safety pre-warning } \\
\text { system. The goal of this infrastructure framework, which is enabled by IoT technology and } \\
\text { association rule mining, is to increase the long-term sustainability of SC quality. }\end{array}$ \\
\hline Porter \& Heppelmann & 2014 & $\begin{array}{l}\text { This study's IoT modelling approach is the first in the field to dissect IoT system design into } \\
\text { ontology-, process-, and object-modelling levels. Also proposed is a novel implementation } \\
\text { architecture for converting IoT system design models to implementation logic. }\end{array}$ \\
\hline Quarshie et al. & 2016 & $\begin{array}{l}\text { The impact of I } 4.0 \text { on the SC is examined in this article, as well as how to assist businesses in } \\
\text { better comprehending the implications of I4.0 and its related technologies in order to attain the } \\
\text { Digital SC, or SC4.0. }\end{array}$ \\
\hline Chukalov & 2017 & $\begin{array}{l}\text { This article presents a proposal architecture for the SC in the context of I4.0, which can be utilized } \\
\text { by each member of the SC to optimize operations in real time, as well as reviewing the design } \\
\text { using a mobile application. }\end{array}$ \\
\hline Kamble et al. & 2018 & $\begin{array}{l}\text { To model and examine the behavior of hospital SCs, as well as to evaluate the impact of cloud- } \\
\text { based information sharing systems, the authors devised a new dynamics approach with a } \\
\text { feedback-based framework. }\end{array}$ \\
\hline Al-Doori & 2019 & $\begin{array}{l}\text { This article explains how blockchain technology can be used to improve SC resilience. It } \\
\text { identifies particular BT to SC risk management operations application areas. }\end{array}$ \\
\hline Khan et al. & 2021 & $\begin{array}{l}\text { The study provides SC practitioners with numerous useful insights into the possible adoption and } \\
\text { exploitation of blockchain technology. }\end{array}$ \\
\hline
\end{tabular}

\begin{tabular}{|c|c|c|}
\hline Technologies & Definition & Reference \\
\hline $\begin{array}{c}\text { Artificial } \\
\text { intelligence }\end{array}$ & $\begin{array}{l}\text { Artefacts' intelligent behaviour was a source of concern. Its goal is to create } \\
\text { machines that can think, reason, learn, communicate, and act like humans in } \\
\text { a complicated environment. }\end{array}$ & (Ghoreishi \& Happonen, 2020) \\
\hline $\begin{array}{l}\text { Cyber physical } \\
\text { system }\end{array}$ & $\begin{array}{l}\text { Engineered systems that are based on the seamless integration of computer } \\
\text { algorithms and physical components and rely on it. }\end{array}$ & $\begin{array}{l}\text { (Babiceanu \& Seker, 2016; } \\
\text { Alguliyev } \text { et al., 2018a; Yaacoub } \\
\text { et al., 2020) }\end{array}$ \\
\hline $\begin{array}{l}\text { Radio-frequency } \\
\text { identification }\end{array}$ & $\begin{array}{l}\text { It may be used to monitor and identify items. It comprises of an RFID tag } \\
\text { that holds the product's unique identification information, a reader that } \\
\text { collects the data from the tag, and a server system that saves the data. }\end{array}$ & $\begin{array}{l}\text { (Dias et al., 2009; Ramanathan et } \\
\text { al., 2014) }\end{array}$ \\
\hline Augmented reality & $\begin{array}{l}\text { Extending physical reality by layering any type of information created by } \\
\text { computers on top of the real world. }\end{array}$ & $\begin{array}{c}\text { (Azuma, 2017; Mourtzis et al., } \\
\text { 2020) }\end{array}$ \\
\hline Internet of things & $\begin{array}{l}\text { Physical and virtual "Things" have identities, physical attributes, virtual } \\
\text { personalities, and use intelligent interfaces, and are seamlessly integrated into } \\
\text { the information network thanks to a dynamic global network infrastructure } \\
\text { with self-configuring capabilities based on standard and interoperable } \\
\text { communication protocols. }\end{array}$ & $\begin{array}{l}\text { (Atzori et al., 2010; Dijkman et } \\
\text { al., 2015; Ben-Daya et al., 2019) }\end{array}$ \\
\hline Blockchain & $\begin{array}{l}\text { A network's dispersed information structure that is reproduced and } \\
\text { exchanged among its members. Cryptography is used to build the blockchain. } \\
\text { Each block is identified by its own cryptographic hash, and each block refers } \\
\text { to the previous block's hash. This establishes a link between the blocks, } \\
\text { forming a blockchain. }\end{array}$ & (Pham, 2018; Azzi et al., 2019) \\
\hline $3 \mathrm{D}$ printing & $\begin{array}{l}\text { It refers to the numerous methods for creating a three-dimensional object. It } \\
\text { makes use of a digital design file that can be turned into a physical thing with } \\
\text { the help of a 3D printer. }\end{array}$ & $\begin{array}{l}\text { (Rindfleisch et al., 2017; Chong } \\
\text { et al., 2018a) }\end{array}$ \\
\hline
\end{tabular}

In SCs, IoT helps to increase warehouse productivity, decrease needless processes, and save time in inventorying (C. K. M. Lee et al., 2018). SC management becomes more effective and efficient because to the Internet of Things. IoT, for example, allows cost savings, inventory accuracy, and product tracking (Ben-Daya et al., 2019). AddoTenkorang and Helo (2016) argue that IoT can help improve products, services, customer experience, and security. Logistics management, database administration, and demand forecasting and planning are the primary areas where CPS can be used effectively. Assimilation of CPS would encourage SC members to work together. It would improve resource and information sharing. It would also improve adaptability to variations in demand (Pham,
2018). CPSs are the foundation of I4.0 because they allow for the digital integration of physical processes through the use of integrated computers and networks to monitor and manage them. These systems have the potential to develop intelligent industries in this environment (Alguliyev et al., 2018b). CPS help with inventory and production control optimization and management (Lee et al., 2015). Blockchain technology has ushered in a new way of thinking about supply chain management (Y. Liu et al., 2017). Across the whole supply chain, blockchain is already helping to transform established business models and create new opportunities (Azzi et al., 2019). Following and sharing data has never been easier, and instant flexibility is now possible thanks to blockchain technology 
(Kamble et al., 2018a). Firms can conduct real-time inventory exchanges via a blockchain-enabled inventory network (Kamble et al., 2018a, b). BT (Bitcoin) plays a crucial role because it is frequently used to mitigate security breaches while ensuring SC availability. BT is hack-proof and has been meticulously engineered to provide automated traceability (Pham, 2018). Blockchain technology allows for the real-time enhancement and tracking of goods and passengers from their beginnings to the end of the supply chain. It aids in the elimination of issues with transparency and accountability (Pham, 2018).

Engineering prototypes are created via $3 \mathrm{D}$ printing. It has the potential to enable large-scale mass customisation of commodities (Chong et al., 2018a). 3DP aids in the reduction of surplus inventory inventories. The number of suppliers can be reduced, and product quality can be improved as a result of the 3DP flexibility. Product variety, shorter lead times, more efficiency, and improved inventory control can all be achieved in the same way (Maresova et al., 2018). The layering of PC reproduction models over the actual architecture of a contemporary environment is referred to as AR. AR increases the efficiency of current SC processes. The majority of common sorts of AR contain a type of glass with a visual presentation for a wearer to employ while boosting profitability and execution. Expanded reality is being used to provide a sense of scene identification when filling out request forms (Rindfleisch et al., 2017). RFID allows for real-time identification, material flow, and tracing, which helps to improve data quality (Ramanathan et al., 2014). The main benefit of RFID technology is that it reduces costs and provides a plethora of data that helps businesses better analyse, predict, and respond to client demand (Chong et al., 2018b). In cellular manufacturing systems, AI approaches are employed for scheduling (Ghoreishi \& Happonen, 2020). In addition, AI is applied in industrial domains through machine vision and autonomous applications. Their performance will be improved by applying predictive technologies that anticipate future scenarios and gain a deep grasp of the interactions in the SC drivers (Tien et al., 2019).

Organizations need a digital supply chain built on visibility, sustainability, and enhanced customer experiences to help them overcome the difficulties of volatility and uncertainty. To put it another way, supply chain transparency reduces the complexity of its processes by increasing visibility of upstream and downstream supply chain operations (A. Agrawal et al., 2015; Almaazmi et al., 2020). As a result, one of the most significant innovations in the fourth SCM revolution is the introduction of CPS into supply chains. The power of an item to recognize the reason for being done, to perform beautifully, and to respond to any changeability in an adaptive manner without the interference of others is defined as "smart" (Kang et al., 2016). SC4.0 is a sophisticated framework with interconnected procedures that evolves from isolated applications to a large, coordinated, and successful relationship between SC stages (Backhaus \& Nadarajah, 2019). The successful digital transformation has created a platform for organizations all over the world to become more efficient from start to finish. However, there is a rising expectation that every SC process will become more efficient, dependable, and transparent as a result of this. As a result, smart SCs make use of data and digital technologies to achieve world-class cost, capital, and client satisfaction outcomes. It provides competitive benefits and opens up new business opportunities. Furthermore, smart SCs connect customers, firms, and distributors to generate transparency, reliability, and effectiveness across the demand to supply value chain through the intelligent use of data. According to Dengler \& Matthes (2018), the following points will be secured thanks to the appropriate application of digital technologies:

(1) Fully integrated SCs: End-to-End (E2E) transparency, a dynamically changeable synchronized network, and global transaction administration via blockchain.

(2) Holistic intelligent E2E decision-making: Real-time data/predictive analysis, real-time performance, and realtime process management.

(3) Automated no-touch SC: Real-time supply and demand planning, automated, smart manufacturing, warehousing, logistics, and customer care.

Companies must use autonomous technology in order to be competitive and have flexibility in their SCs. These motives encourage organizations to deploy SCM4.0, as indicated in Table A2 in Appendix 2. As a result, corporations choose to adopt novel technology to boost system performance and worker productivity. Income growth is fuelled by digital investments that reduce expenses and simplify SC complexity. As a result, firms view customer satisfaction, partner connections, and production quantities as important drivers in the SC procedures for implementing digitization. The benefits of SCM4.0 integration are undeniable, but it also brings with it some challenges and roadblocks. Companies that have selected or have already implemented digital technologies face problems such as the cost of technical set-up and extensive development times, as shown in Table 6 . Digitalization deployment is also hampered by a lack of coordination and a sense of urgency. Leaders can help their employees overcome these barriers by highlighting the value of emerging technology for the SC and providing ongoing guidance and a clear strategic goal.

TABLE V : INTELLIGENT SCM DRIVERS.

\begin{tabular}{|c|c|}
\hline Drivers & References \\
\hline Industrial improvement & (Al-Doori, 2019) \\
\hline Autonomous systems & (Lee et al., 2018) \\
\hline Big data handling & $\begin{array}{c}\text { (Addo-Tenkorang \& Helo, } \\
\text { 2016) }\end{array}$ \\
\hline $\begin{array}{l}\text { Improved supply chain } \\
\text { performance }\end{array}$ & (Al-Doori, 2019) \\
\hline $\begin{array}{l}\text { End-to-End visibility and } \\
\text { connectivity }\end{array}$ & (Agrawal et al., 2015) \\
\hline $\begin{array}{c}\text { Self-aware and learning } \\
\text { machines }\end{array}$ & (Carvalho et al., 2019) \\
\hline Elimination of waste and errors & (Gökalp et al., 2017) \\
\hline Improved quality & (Fernandes et al., 2017) \\
\hline Increased flexibility and agility & (R. Kumar \& Mishra, 2017) \\
\hline \multicolumn{2}{|c|}{ TABLE VI : INTELLIGENT SCM BARRIERS } \\
\hline Barriers & References \\
\hline Lack of integration & (Chukalov, 2017) \\
\hline
\end{tabular}




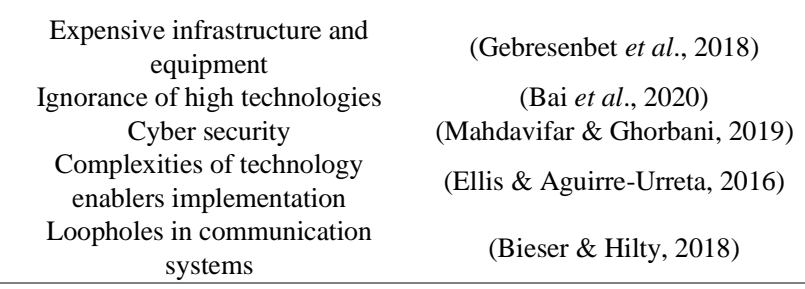

\section{STUDY FRAMEWORK: DEVELOPMENT OF INTELLIGENT SCM}

Because it involves unique activity flows, elements, features, and role players, the SCM 4.0 subject is tough to grasp. Fig. 5 depicts the initial framework, which serves as a road map for a better understanding of SCM4.0. The suggested framework decomposes the link between diverse sections inside digital SCs, based on the literature evaluation.

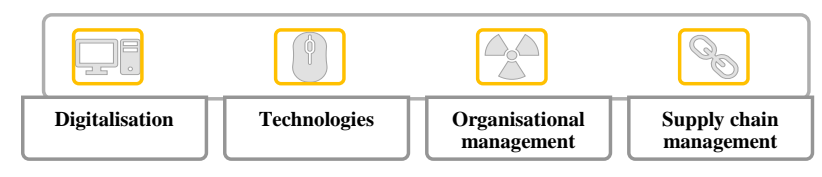

Fig. 5. Intelligent supply chain framework.

By defining essential subjects in SCM 4.0, assessing current SCM categorizations, and analysing previous frameworks, the framework was created. Researchers and practitioners in the subject can use this framework as a guide. The framework's goal is to bring together the most important issues and ideas in SCM4.0. For its creation, the following elements were considered:

Any SC's job is to move equipment, finished goods, capital, and other resources from one site to another. SCs are a collection of activities that exchange time, money, data, or physical equipment for a different value unit. Fernandes et al. (2017) define SCs as "end-to-end information, products and services, and cash flows." As a result, addressing these factors has an impact on an organization's competitive positioning in areas like product pricing, working capital requirements, speed-to-market, and customer perception of service. Organizations are looking for innovative methods to streamline their SCs in order to meet shifting consumer demands. Traditional SCs have been impacted by tremendous technical and digital advancements in various ways, including increased computing power and lower general expenses, as well as lower transaction costs and increased innovation in manufacturing processes.

Digital technologies help businesses solve challenges, develop new possibilities, acquire a competitive advantage, and improve their performance (Reis et al., 2018; Siedler et al., 2019). By incorporating modern technologies into classic linear SCs with a discrete movement of "plan, source, make, deliver, and return," SCs are transformed from static to dynamic (Gattorna, 2016). This shift from linear, sequential production network activities to an interconnected, open supply task structure is critical for enterprises to compete in the future. As each supply process becomes more proficient and connected, the SC transforms into a dynamic, integrated supply system. SC4.0 refers to the transformation of SCs using I4.0 technologies. Companies in high-income countries are primarily introducing these technologies, which arose in the twenty-first century. These businesses want to keep their SCs competitive. SC4.0 entails deploying modern instruments such as the Internet of Things (IoT), Big Data Analytics (BDA), Autonomous Robotics (AR), and so on (Ellis \& Aguirre-Urreta, 2016). It converts the SCM model from a linear model (Fernandes et al., 2017) to a more integrated model (R. Kumar \& Mishra, 2017) with omnidirectional data flows. In other words, technological advancements are revolutionizing the exchange and sharing of data and resources between enterprises by converting linear SCs into dynamically linked and continuing digital supply networks.

Successful firms must establish appropriate digital projects that are linked with their goals, learn quickly from trial implementations, and be determined and capable of scaling. To meet the dual challenge of attracting talent and improving employees working on traditional SCs, managers should: (1) diversify their recruitment strategy; (2) create an environment that encourages learning; (3) create a clear career path for employees; (4) empower talent to lead change; and (5) create appropriate programs for learning new skills.

Companies are adamant about introducing new products, technical advancements, and administrative changes in order to provide extra value for both their clients and themselves. Agrawal et al. (2015) believe that digitalization can help them attain these goals and improve SC operations. The fourth SCM revolution is currently underway, and each company must reconsider how to implement and use it. Digitization has already changed the way we operate in the field of data leadership (Bukht \& Heeks, 2017). Heavy expenditure and considerable digitization-related hurdles stymie the implementation of digital SCs (Ardito et al., 2019). Due to the risky nature of digital SC systems, focal enterprises must modify external settings and many other parties, many of whom are outside their control (Liu et al., 2019).

SC's digitalization has a plethora of benefits (Palang \& Tippayawong, 2019) .Companies want durable, secure, and long-lasting SCs, which can be created with new technologies for instrumentation, interconnection, and intelligence. Smarter SCs would evaluate only the information they needed and make sense of it via smart modelling (Rashid \& Tjahjono, 2016). Increased flexibility, quality standards, efficiency, and productivity are the most important advantages. BDA, cloud technology, cybersecurity, IoT, downsizing of electronics, RFID, robots, drones, and nanotechnology, on the other hand, can all be risks to businesses (Chernov \& Sornette, 2020). Furthermore, the benefits of better supply chains usually translate into a price increase for items (Machado et al., 2019). As the volume of digitalized data grows and the number of Internet companies grows, the risk of assaults on their databases grows as well. Hackers may want to change, steal, or remove information (Degryse, 2016). 
Investment in technology has become critical in boosting industries' "competitiveness" (Spillan et al., 2018). The factors that make these technologies so important to SCs, however, also make them vulnerable. Furthermore, thanks to enabling technologies, the entire industrial process is now more open and integrated (Chukalov, 2017). This means that information delays are reduced to near-real-time levels, and miscommunications and even missed communications are no longer an issue. The system's secrecy will be jeopardized as a result of this transparency (Bieser \& Hilty, 2018). In other words, interconnecting the various devices and exchanging information with external parties such as consumers implies that the firm's system is vulnerable to a large number and variety of assaults, as shown in Table 4. Furthermore, international networks rely heavily on technological advancements not just to manage SC complexity but also to ensure its efficacy (Zheng et al., 2019). This dependability will make them more vulnerable to cyber-attacks (Finnemore \& Hollis, 2016).

Companies that use digital SC frameworks to coordinate and transact with their partners face significant risks (Xue et al., 2017). Furthermore, in the fourth industrial revolution era, the digital transformation produces a level of complexity and uncertainty that threatens SCs (Zhong et al., 2020). As a result, new dangers are posed to businesses as a result of the development and acceptance of multiple technologies, notably in the SC (R. Kumar \& Mishra, 2017). Malware, cyberattacks, spyware, and data loss are examples of dangers that might have a substantial influence on various production methods (Kumar \& Reinartz, 2016). To summarize, businesses are confronted with the task of incorporating modern supply chain technologies. However, since hackers target manufacturing processes, appropriately safeguarding digital SCs is a major concern (Siedler et al., 2019). Economic losses exceeding \$1 trillion in annual revenue losses for the entire industry are the result of such cyberattacks (Mahdavifar \& Ghorbani, 2019).

Diverse competences must be in place in order to develop resilient supply chains (Mackay et al., 2020). Stakeholders should concentrate on detecting, monitoring, and analysing risks in order to minimize negative consequences (Chernov \& Sornette, 2020). In a digital SC, risk control and management will be focused on resolving third-party cybersecurity and delivering swift organizational responses to unforeseen incidents. Furthermore, security systems for SCM4.0 must be able to identify security events, secure vital structures, apply the necessary safeguarding measures, respond to threats in real time, and recover from any attack if it occurs (Ghobakhloo, 2018). Using a risk monitor system based on BD and warning indicators, organizations will be able to keep one step ahead of their competition if they are attacked, thanks to emerging technology.

\section{CONCLUSION}

This is the first article to examine the available literature on SCM4.0 published between 1994 and 2021 in order to establish a roadmap framework for SCM4.0 implementation. As a result, in order to foster study in the subject of digital supply chain management, the gaps in the existing literature, future research topics, and implications for practitioners are identified. A literature review was used to examine SCM4.0 in this paper. The following research gaps were discovered as a result of this analysis:

(1) There is no structure in the area that gives a roadmap for implementing SCM 4.0. There are no strategic or explicit instructions for implementing SCM 4.0 in the present frameworks. Organizations would benefit from having a blueprint for how to digitalize their SCs. The roadmap should take into account the many resources that are required (e.g., financial, human competencies, legal, ethics, environment).

(2) None of the 176 papers found discussed the SC abilities required in the I4.0 timeframe. New occupations will be created as SCs become more digital. Those positions will be devoted to new skills. As a result, the former should be well-known in order to be integrated in the educational system of new graduates and reorient the labour market.

(3) There aren't enough articles about SCM4.0 in numerous industries, such as food, fashion, and so forth. Despite the fact that the automobile industry plays a vital role in the evolution of technology research and application, no article examining a real-world implementation of SCM4.0 in this industry has been found.

(4) The bibliometric research revealed that there is a dearth of discussion regarding digital and smart SCs outside of its facilitators (novel technologies). To put it another way, studies on Digital SCM are insufficient to fully comprehend all of the changes that have occurred along the value chain. Furthermore, none of the publications discuss the digitalization of each SC process. (5) There was also a paucity of study on the implementation and sustainability challenges of SCM4.0. Despite the importance of sustainability in maintaining a competitive advantage, none of the studies that were chosen looked into the SC's coexistence of sustainability and smartness. Furthermore, the impact of digitalization on the many aspects of SC sustainability is not addressed.

(5) The impacts of implementing SCM 4.0 on human performance were not investigated in any of the 176 studies examined. Any organization's core is its people. As a result, it is critical to employ technologies that help to increase productivity while avoiding negative consequences for human health and safety. Furthermore, no studies on the likelihood of people losing their jobs have been undertaken. To put it another way, the fact that new technology is replacing human competencies or that digitalization is creating new jobs should be celebrated.

There are four major consequences for theory and practice in this study. For starters, it provides a solid foundation for SCM4.0 in the digitalization era. Second, the literature review provides fresh perspectives on the topic by outlining motivations, barriers, and the influence of technology. Third, it can serve as a resource for scholars who want to get a better understanding of SCM 4.0's background and concerns to address in future study. Finally, a hypothesized framework for implementing 
SCM4.0 is created, which can be used as a roadmap in future research. The study adds to the SCM4.0 literature because it is the first to focus on both SCM4.0 and its technology.

The framework that has been established contains a number of features that may motivate scientists and practitioners to use it. It provides a simple, easy-tounderstand graphical depiction of SCM4.0. It also emphasizes proving the link between modules in the field. The framework serves as both an explanation tool and a path map. As a result, the suggested SCM4.0 framework will be used in a real-world industry application, such as the digitization of an automotive SC. There are several limitations to this paper that provide chances for future research. The suggested understanding framework is intended to aid in the general comprehension of SCM4.0. As a result, it doesn't go into great detail about the third level of the SCM 4.0 system. As a result, future research might enlarge the framework while focusing on individual components. To put it another way, the current framework can be expanded, and the importance of the many subcomponents and elements can be investigated.

\section{REFERENCES}

Abdelkafi, N., \& Pero, M. (2018). Supply chain innovation-driven business models: Exploratory analysis and implications for management. Business Process Management Journal, 24(2), 589608. https://doi.org/10.1108/BPMJ-05-2016-0109.

Addo-Tenkorang, R., \& Helo, P. T. (2016). Big data applications in operations/supply-chain management: A literature review. Computers \& Industrial Engineering, 101, 528-543. https://doi.org/10.1016/j.cie.2016.09.023.

Agrawal, A., Horton, J., Lacetera, N., \& Lyons, E. (2015). Digitization and the contract labor market: A research agenda. In Economic analysis of the digital economy (pp. 219-250). University of Chicago Press.

Agrawal, S., Singh, R. K., \& Murtaza, Q. (2015). A literature review and perspectives in reverse logistics. Resources, Conservation and Recycling, 97, 76-92. https://doi.org/10.1016/j.resconrec.2015.02.009.

Al-Doori, J. A. (2019). The impact of supply chain collaboration on performance in automotive industry: Empirical evidence. Journal of Industrial Engineering and Management, 12(2), 241-253. https://doi.org/10.3926/jiem.2835.

Alguliyev, R., Imamverdiyev, Y., \& Sukhostat, L. (2018a). Cyberphysical systems and their security issues. Computers in Industry, 100, 212-223. https://doi.org/10.1016/j.compind.2018.04.017.

Alguliyev, R., Imamverdiyev, Y., \& Sukhostat, L. (2018b). Cyberphysical systems and their security issues. Computers in Industry, 100, 212-223. https://doi.org/10.1016/j.compind.2018.04.017.

Almaazmi, J., Alshurideh, M., Al Kurdi, B., \& Salloum, S. A. (2020). The Effect of Digital Transformation on Product Innovation: A Critical Review. International Conference on Advanced Intelligent Systems and Informatics, 731-741.

Al-Mudimigh, A. S., Zairi, M., \& Ahmed, A. M. M. (2004). Extending the concept of supply chain: International Journal of Production Economics, 87(3), 309-320. https://doi.org/10.1016/j.ijpe.2003.08.004.

Ameri, F., \& Patil, L. (2012). Digital manufacturing market: A semantic web-based framework for agile supply chain deployment. Journal of Intelligent Manufacturing, 23(5), 1817-1832. https://doi.org/10.1007/s10845-010-0495-z.

Ardito, L., Petruzzelli, A. M., Panniello, U., \& Garavelli, A. C. (2019). Towards Industry 4.0: Mapping digital technologies for supply chain management-marketing integration. Business Process Management Journal.

Atzori, L., Iera, A., \& Morabito, G. (2010). The Internet of Things: A survey. Computer Networks, 54(15), 2787-2805. https://doi.org/10.1016/j.comnet.2010.05.010.

Azuma, R. T. (2017). Making Augmented Reality a Reality. Imaging and
Applied Optics 2017 (3D, AIO, COSI, IS, MATH, PcAOP), JTu1F.1. https://doi.org/10.1364/3D.2017.JTu1F.1 .

Azzi, R., Chamoun, R. K., \& Sokhn, M. (2019). The power of a blockchain-based supply chain. Computers \& Industrial Engineering, 135, https://doi.org/10.1016/j.cie.2019.06.042.

Babiceanu, R. F., \& Seker, R. (2016). Big Data and virtualization for manufacturing cyber-physical systems: A survey of the current status and future outlook. Computers in Industry, 81, 128-137. https://doi.org/10.1016/j.compind.2016.02.004.

Backhaus, S. K. H., \& Nadarajah, D. (2019). Investigating the relationship between industry 4.0 and productivity: A conceptual framework for Malaysian manufacturing firms. Procedía Computer Science, 161, 696-706.

Bai, C., Dallasega, P., Orzes, G., \& Sarkis, J. (2020). Industry 4.0 technologies assessment: A sustainability perspective. International Journal of Production Economics, 229, 107776. https://doi.org/10.1016/j.ijpe.2020.107776.

Barholomae. (2018). Digital Transformation, International Competition and Specialization. 7.

Ben-Daya, M., Hassini, E., \& Bahroun, Z. (2019). Internet of things and supply chain management: A literature review. International Journal of Production Research, 57(15-16), 4719-4742. https://doi.org/10.1080/00207543.2017.1402140.

Bhatti, Chandran, \& Sundram. (2016). Supply chain practices and performance: The indirect effects of supply chain integration. https://www.emerald.com/insight/content/doi/10.1108/BIJ-032015-0023/full/html.

Bieser, J. C., \& Hilty, L. M. (2018). Assessing indirect environmental effects of information and communication technology (ICT): A systematic literature review. Sustainability, 10(8), 2662.

Bu, L., Chen, C.-H., Zhang, G., Liu, B., Dong, G., \& Yuan, X. (2020). A hybrid intelligence approach for sustainable service innovation of smart and connected product: A case study. Advanced Engineering Informatics, 46, 101163.

Bukht, R., \& Heeks, R. (2017). Defining, conceptualising and measuring the digital economy. Development Informatics Working Paper, 68.

Carbone, V., \& Gouvernal, E. (2007). Supply chain and supply chain management: Appropriate concepts for maritime studies. International Workshop on Ports, Cities and Global Supply Chains (2005: Hong Kong, China). https://trid.trb.org/view/859332.

Carvalho, T. P., Soares, F. A. A. M. N., Vita, R., Francisco, R. da P., Basto, J. P., \& Alcalá, S. G. S. (2019). A systematic literature review of machine learning methods applied to predictive maintenance. Computers \& Industrial Engineering, 137, 106024. https://doi.org/10.1016/j.cie.2019.106024.

Chernov, D., \& Sornette, D. (2020). Specific Features of Risk Management in the Service Sector. In D. Chernov \& D. Sornette (Eds.), Critical Risks of Different Economic Sectors: Based on the Analysis of More Than 500 Incidents, Accidents and Disasters (pp. 147-261). Springer International Publishing. https://doi.org/10.1007/978-3-030-25034-83.

Chong, S., Pan, G.-T., Chin, J., Show, P., Yang, T., \& Huang, C.-M (2018a). Integration of 3D Printing and Industry 4.0 into Engineering Teaching. Sustainability, 10(11), 3960. https://doi.org/10.3390/su10113960.

Chong, S., Pan, G.-T., Chin, J., Show, P., Yang, T., \& Huang, C.-M. (2018b). Integration of 3D Printing and Industry 4.0 into Engineering Teaching. Sustainability, 10(11), 3960. https://doi.org/10.3390/su10113960.

Christopher, M. (2005). Logistics and supply chain management: Creating value-added networks (3rd ed). FT Prentice Hall.

Chukalov, K. (2017). Horizontal and vertical integration, as a requirement for cyber-physical systems in the context of industry 4.0. Industry 4.0, 2(4), 155-157.

Degryse, C. (2016). Digitalisation of the economy and its impact on labour markets. ETUI Research Paper-Working Paper.

Dengler, K., \& Matthes, B. (2018). The impacts of digital transformation on the labour market: Substitution potentials of occupations in Germany. Technological Forecasting and Social Change, 137, 304-316.

Dias, J. C. Q., Calado, J. M. F., Osório, A. L., \& Morgado, L. F. (2009). RFID together with multi-agent systems to control global value chains. Annual Reviews in Control, 33(2), 185-195. https://doi.org/10.1016/j.arcontrol.2009.03.005

Dijkman, R. M., Sprenkels, B., Peeters, T., \& Janssen, A. (2015). Business models for the Internet of Things. International Journal of Information Management, 35(6), 672-678. https://doi.org/10.1016/j.ijinfomgt.2015.07.008.

Ellis, M. E., \& Aguirre-Urreta, M. I. (2016). Categorization of 
Technologies: Insights from the Technology Acceptance Literature. 11.

Emelogu, A., Chowdhury, S., Marufuzzaman, M., \& Bian, L. (2019). Distributed or centralized? A novel supply chain configuration of additively manufactured biomedical implants for southeastern US States. CIRP Journal of Manufacturing Science and Technology, 24, 17-34. https://doi.org/10.1016/j.cirpj.2018.12.001

Fernandes, A. C., Sampaio, P., Sameiro, M., \& Truong, H. Q. (2017). Supply chain management and quality management integration: A conceptual model proposal. International Journal of Quality \& Reliability Management, 34(1), 53-67. https://doi.org/10.1108/IJQRM-03-2015-0041.

Finnemore, M., \& Hollis, D. B. (2016). Constructing Norms for Global Cybersecurity. The American Journal of International Law, 110(3), 425-479.

Gattorna, J. (2016). Dynamic Supply Chain Alignment: A New Business Model for Peak Performance in Enterprise Supply Chains Across All Geographies. CRC Press.

Gebresenbet, G., Bosona, T., Olsson, S.-O., \& Garcia, D. (2018). Smart system for the optimization of logistics performance of the pruning biomass value chain. Applied Sciences, 8(7), 1162.

Ghobakhloo, M. (2018). The future of manufacturing industry: A strategic roadmap toward Industry 4.0. 27.

Ghoreishi, M., \& Happonen, A. (2020). Key enablers for deploying artificial intelligence for circular economy embracing sustainable product design: Three case studies. AIP Conference Proceedings, 2233(1), 050008

Gökalp, E., Şener, U., \& Eren, P. E. (2017). Development of an Assessment Model for Industry 4.0: Industry 4.0-MM. In A. Mas, A. Mesquida, R. V. O'Connor, T. Rout, \& A. Dorling (Eds.), Software Process Improvement and Capability Determination (Vol. 770, pp. 128-142). Springer International Publishing. https://doi.org/10.1007/978-3-319-67383-7_10.

Kamble, S. S., Gunasekaran, A., \& Gawankar, S. A. (2018a). Sustainable Industry 4.0 framework: A systematic literature review identifying the current trends and future perspectives. Process Safety and Environmental Protection, 117, 408-425.

Kamble, S. S., Gunasekaran, A., \& Gawankar, S. A. (2018b). Sustainable Industry 4.0 framework: A systematic literature review identifying the current trends and future perspectives. Process Safety and Environmental Protection, 117, 408-425. https://doi.org/10.1016/j.psep.2018.05.009.

Kang, H. S., Lee, J. Y., Choi, S., Kim, H., Park, J. H., Son, J. Y., Kim, B. H., \& Noh, S. D. (2016). Smart manufacturing: Past research, present findings, and future directions. International Journal of Precision Engineering and Manufacturing-Green Technology, 3(1), 111-128. https://doi.org/10.1007/s40684-016-0015-5.

Khan, S., Haleem, A., \& Khan, M. I. (2021). Assessment of risk in the management of Halal supply chain using fuzzy BWM method. Supply Chain Forum: An International Journal, 22(1), 57-73.

Kumar, R., \& Mishra, M. (2017). Manufacturing and supply chain flexibility: An integrated viewpoint. International Journal of Services and Operations Management, 27(3), 384-407. https://doi.org/10.1504/IJSOM.2017.084447.

Kumar, V., \& Reinartz, W. (2016). Creating Enduring Customer Value. Journal of Marketing, 80(6), 36-68. https://doi.org/10.1509/jm.15.0414

Lee, C. K. M., Lv, Y., Ng, K. K. H., Ho, W., \& Choy, K. L. (2018). Design and application of Internet of things-based warehouse management system for smart logistics. International Journal of Production Research, 56(8), 2753-2768.

Lee, J., Bagheri, B., \& Kao, H.-A. (2015). A Cyber-Physical Systems architecture for Industry 4.0-based manufacturing systems. Manufacturing Letters, 3, 18-23. https://doi.org/10.1016/j.mfglet.2014.12.001.

Liu, T., Tang, H., \& Xue, F. (2019). A Joint Adjustment System for Distributed Logistics Equipment. DEStech Transactions on Computer Science and Engineering, 0(aicae), Article aicae. https://doi.org/10.12783/dtcse/aicae2019/31479.

Liu, Y., Peng, Y., Wang, B., Yao, S., \& Liu, Z. (2017). Review on cyberphysical systems. IEEE/CAA Journal of Automatica Sinica, 4(1), 27-40. https://doi.org/10.1109/JAS.2017.7510349.

Machado, C. G., Winroth, M., Carlsson, D., Almström, P., Centerholt, V., \& Hallin, M. (2019). Industry 4.0 readiness in manufacturing companies: Challenges and enablers towards increased digitalization. Procedia CIRP, 81, 1113-1118. https://doi.org/10.1016/j.procir.2019.03.262.

Mackay, J., Munoz, A., \& Pepper, M. (2020). Conceptualising redundancy and flexibility towards supply chain robustness and resilience. Journal of Risk Research, 23(12), 1541-1561. https://doi.org/10.1080/13669877.2019.1694964.

Mahdavifar, S., \& Ghorbani, A. A. (2019). Application of deep learning to cybersecurity: A survey. Neurocomputing, 347, 149-176. https://doi.org/10.1016/j.neucom.2019.02.056.

Maresova, P., Soukal, I., Svobodova, L., Hedvicakova, M., Javanmardi, E., Selamat, A., \& Krejcar, O. (2018). Consequences of industry 4.0 in business and economics. Economies, 6(3), 46.

Mourtzis, D., Siatras, V., \& Angelopoulos, J. (2020). Real-Time Remote Maintenance Support Based on Augmented Reality (AR). Applied Sciences, 10(5), 1855. https://doi.org/10.3390/app10051855.

Palang, D., \& Tippayawong, K. Y. (2019). Performance evaluation of tourism supply chain management: The case of Thailand. Business Process Management Journal, 25(6), 1193-1207. https://doi.org/10.1108/BPMJ-05-2017-0124.

Pham, H. (2018). The impact of Blockchain Technology on the improvement of Food Supply Chain Management: Transparency and Traceability: A case study of Walmart and Atria [Fi=AMKopinnäytetyö|sv=YH-examensarbete|en=Bachelor's thesis|] Seinäjoen ammattikorkeakoulu. http://www.theseus.fi/handle/10024/157299.

Porter, M. E., \& Heppelmann, J. E. (2014). How Smart, Connected Products Are Transforming Competition. 23.

Quarshie, A. M., Salmi, A., \& Leuschner, R. (2016). Sustainability and corporate social responsibility in supply chains: The state of research in supply chain management and business ethics journals. Journal of Purchasing and Supply Management, 22(2), 82-97. https://doi.org/10.1016/j.pursup.2015.11.001.

Ramanathan, R., Ramanathan, U., \& Ko, L. W. L. (2014). Adoption of RFID technologies in UK logistics: Moderating roles of size, barcode experience and government support. Expert Systems with Applications, 41(1), 230-236. https://doi.org/10.1016/j.eswa.2013.07.024.

Rashid, A., \& Tjahjono, B. (2016). Achieving manufacturing excellence through the integration of enterprise systems and simulation. Production Planning \& Control, 27(10), 837-852.

Reis, J., Amorim, M., Melão, N., \& Matos, P. (2018). Digital transformation: A literature review and guidelines for future research. World Conference on Information Systems and Technologies, 411-421.

Rindfleisch, A., O’Hern, M., \& Sachdev, V. (2017). The digital revolution, 3D printing, and innovation as data. Journal of Product Innovation Management, 34(5), 681-690.

Siedler, C., Langlotz, P., \& Aurich, J. C. (2019). Identification of interactions between digital technologies in manufacturing systems. Procedia CIRP, 81, 115-120. https://doi.org/10.1016/j.procir.2019.03.021

Spillan, J. E., Mintu-Wimsatt, A., \& Kara, A. (2018). Role of logistics strategy, coordination and customer service commitment on Chinese manufacturing firm competitiveness. Asia Pacific Journal of Marketing and Logistics, 30(5), 1365-1378. https://doi.org/10.1108/APJML-09-2017-0224.

Stock, T., \& Seliger, G. (2016). Opportunities of Sustainable Manufacturing in Industry 4.0. Procedia CIRP, 40, 536-541. https://doi.org/10.1016/j.procir.2016.01.129.

Tien, N. H., Anh, D. H., \& Thuc, T. D. (2019). Global Supply Chain And Logistics Management. 2019, 176.

Vatovec, E. (2011). Intelligent Value Chain Networks: Business Intelligence and Other ICT Tools and Technologies in Supply/Demand Chains. In S. Renko (Ed.), Supply Chain Management - New Perspectives. InTech. https://doi.org/10.5772/18850.

Wu, H., Li, Z., King, B., Ben Miled, Z., Wassick, J., \& Tazelaar, J. (2017). A distributed ledger for supply chain physical distribution visibility. Information, 8(4), 137.

Wu, I.-L., Chuang, C.-H., \& Hsu, C.-H. (2014). Information sharing and collaborative behaviors in enabling supply chain performance: A social exchange perspective. International Journal of Production Economics, 148 , https://doi.org/10.1016/j.ijpe.2013.09.016

Xue, L., Liu, G., Parfitt, J., Liu, X., Van Herpen, E., Stenmarck, \AAsa, O’Connor, C., Östergren, K., \& Cheng, S. (2017). Missing food, missing data? A critical review of global food losses and food waste data. Environmental Science \& Technology, 51(12), 6618-6633.

Yaacoub, J.-P. A., Salman, O., Noura, H. N., Kaaniche, N., Chehab, A. \& Malli, M. (2020). Cyber-physical systems security: Limitations, issues and future trends. Microprocessors and Microsystems, 77 103201. https://doi.org/10.1016/j.micpro.2020.103201.

Zare Mehrjerdi, Y. (2009). Excellent supply chain management. Assembly Automation, 29(1), 52-60. https://doi.org/10.1108/01445150910929866. 
www.ejbmr.org

Zheng, Y., Ren, D., Guo, Z., Hu, Z., \& Wen, Q. (2019). Research on integrated resource strategic planning based on complex uncertainty simulation with case study of China. Energy, 180, 772-786.

Zhong, Y., Fangfang, G., Tang, H., \& Chen, X. (2020). Research on Coordination Complexity of E-Commerce Logistics Service Supply Chain.

https://www.hindawi.com/journals/complexity/2020/7031543/. 